\title{
Elevated amniotic fluid amino acid levels in fetuses with gastroschisis
}

\section{A. Kale , E. Kale², \\ N. Akdeniz ${ }^{1}$ \\ and N. Canoruc ${ }^{2}$}

\author{
${ }^{1}$ Department of Obstetrics and Gynecology, ${ }^{2}$ Department of Clinical Biochemistry, \\ Dicle University School of Medicine, Diyarbakir, Turkey
}

\begin{abstract}
Correspondence

A. Kale

Department of Obstetrics and

Gynecology

Dicle University School of Medicine

21280 Diyarbakir

Turkey

E-mail: drakale@dicle.edu.tr

Received November 24, 2005

Accepted April 26, 2006

$\ldots \ldots \ldots \ldots \ldots \ldots \ldots$

Our objective was to measure maternal plasma and amniotic fluid amino acid concentrations in pregnant women diagnosed as having fetuses with gastroschisis in the second trimester of pregnancy. Twentyone pregnant women who had fetuses with gastroschisis detected by ultrasonography (gastroschisis group) in the second trimester and 32 women who had abnormal triple screenings indicating an increased risk for Down syndrome but had healthy fetuses (control group) were enrolled in the study. Amniotic fluid was obtained by amniocentesis, and maternal plasma samples were taken simultaneously. The chromosomal analysis of the study and control groups was normal. Levels of free amino acids and non-essential amino acids were measured in plasma and amniotic fluid samples using EZ:fast kits (EZ:fast GC/FID free (physiological) amino acid kit) by gas chromatography (Focus GC AI 3000 Thermo Finnigan analyzer). The mean levels of essential amino acids (histidine, isoleucine, leucine, lysine, methionine, phenylalanine, threonine, tryptophan, and valine) and non-essential amino acids (alanine, glycine, proline, and tyrosine) in amniotic fluid were found to be significantly higher in fetuses with gastroschisis than in the control group $(\mathrm{P}<0.05)$. A significant positive correlation between maternal plasma and amniotic fluid concentrations of essential and nonessential amino acids was found only in the gastroschisis group $(\mathrm{P}<0.05)$. The detection of significantly higher amino acid concentrations in the amniotic fluid of fetuses with a gastroschisis defect than in healthy fetuses suggests the occurrence of amino acid malabsorption or of amino acid leakage from the fetus into amniotic fluid.
\end{abstract}

\section{Introduction}

Gastroschisis is a full thickness abdominal wall defect in which the viscera herniate through the abdominal wall lateral to the umbilicus. This condition occurs in 1 to 3 per 10,000 live births and, unlike exomphalos, the viscera are not surrounded by a membra-
Key words

- Amino acids

- Gastroschisis

- Amniotic fluid 
pregnancy and infants with gastroschisis almost universally experience problems with absorptive and motility functions of the intestine which are the major cause of mortality and morbidity (3).

Bowel loops may become dilated due to partial lymphatic and venous obstruction caused by obstruction on the side wall of the defect. Severe complications, such as volvulus, atresia, ischemia, increased mucosal permeability, and intestinal villous atrophy, result in increased mortality and morbidity (4). Furthermore, animal models of gastroschisis have shown that there is a significant deficiency in nutrient absorption and protein concentration in the small bowel after prolonged exposure to amniotic fluid $(3,5)$.

The aim of the present study was to determine the concentrations of amino acids in amniotic fluid and maternal serum of pregnant women whose fetuses were diagnosed to have gastroschisis in the second trimester of pregnancy. We hypothesized that the concentrations of amino acids may be higher in fetuses with gastroschisis due to deficiency in nutrient absorption, intestinal dysfunction and increased mucosal permeability of the intestines.

\section{Patients, Material and Methods}

The study was performed at the Prenatal

Table 1. Demographic characteristics of the study and control groups.

\begin{tabular}{|c|c|c|}
\hline & $\begin{array}{l}\text { Gastroschisis group } \\
\qquad(N=21)\end{array}$ & $\begin{array}{l}\text { Control group } \\
\qquad(\mathrm{N}=32)\end{array}$ \\
\hline Maternal age (years) & $25.5 \pm 2.01$ & $24.7 \pm 3.1$ \\
\hline Nulliparity & $7(30 \%)$ & $9(29 \%)$ \\
\hline $\begin{array}{l}\text { Gestational age at the time of amniocentesis } \\
\text { (weeks) }\end{array}$ & $19.1 \pm 1.1$ & $18.6 \pm 1.0$ \\
\hline $\begin{array}{l}\text { Maternal body mass index at the time of } \\
\text { amniocentesis }\left(\mathrm{kg} / \mathrm{m}^{2}\right)\end{array}$ & $26.2 \pm 1.0$ & $25.9 \pm 1.1$ \\
\hline
\end{tabular}

Data are reported as means \pm SD. There were no statistically significant differences between groups (Student $t$-test, $\mathrm{P}>0.05$ ).
Diagnosis Unit of Dicle University Hospital between January 2002 and June 2005. The study was approved by the institutional review board and Ethics Committee of the university hospital, and written informed consent was obtained from all participants. All pregnant women who had a fetus with gastroschisis $(\mathrm{N}=21)$ in the second trimester were included in the study. The first 32 women who attended our clinic and had abnormal triple screens indicating an increased risk for Down syndrome were included in the study as the control group. Mean maternal age was $25.5 \pm 2.01$ years for the gastroschisis group and $24.7 \pm 3.1$ years for the study group. The mean gestational age at sampling was $19.1 \pm 1.1$ weeks for the gastroschisis group and 18.6 \pm 1.0 weeks for the study group. Maternal body mass index was $26.2 \pm 1.0 \mathrm{~kg} / \mathrm{m}^{2}$ in gastroschisis group and $25.9 \pm 1.1 \mathrm{~kg} / \mathrm{m}^{2}$ in the study group. Seven women in the gastroschisis group and 9 in the control group were nulliparous (Table 1).

Obese patients and those with any systemic or endocrine disorder were excluded from the study. All pregnancies were accurately dated by the last menstrual period and by first-trimester ultrasonographic investigation. Amniotic fluid samples were obtained by routine transabdominal amniocentesis and collected into $10-\mathrm{mL}$ dry tubes. All amniotic fluid samples were free of blood contamination. Venous blood samples were taken within $10 \mathrm{~min}$ after amniocentesis from the pregnant women and collected into EDTA-containing tubes. All samples were immediately centrifuged at $3000 \mathrm{~g}$ for 10 min and stored at $-20^{\circ} \mathrm{C}$ until assayed. Levels of free amino acids (essential amino acids: histidine, leucine, lysine, isoleucine, methionine, phenylalanine, threonine, tryptophan, and valine) and non-essential amino acids (alanine, asparagine, aspartic acid, cystathionine, cysteine, glutamic acid, glutamine, glycine, ornithine, and proline) were measured in plasma and amniotic fluid 
samples using EZ:fast kits (EZ:fast GC/FID free (physiological) amino acid kit) by gas chromatography (Focus GC AI 3000 Thermo Finnigan analyzer, Milan, Italy; injection: Split 1:15 at $250^{\circ} \mathrm{C}, 2.5 \mu$; carrier gas: helium $1.5 \mathrm{~mL} / \mathrm{min}(60 \mathrm{kPa})$ at $110^{\circ} \mathrm{C}$; pressure rise: $6 \mathrm{kPa} / \mathrm{min}$; oven program: $30^{\circ} \mathrm{C} / \mathrm{min}$ from $110^{\circ}$ to $320^{\circ} \mathrm{C}$, hold at $320^{\circ}$ for $1 \mathrm{~min}$; Detector: FID at $320^{\circ} \mathrm{C}$; intravariability: $2.4 \%$; intervariability: $3.2 \%$ ).

The results are reported as means $\pm \mathrm{SD}$. A $t$-test was performed for statistical analysis. The statistical relationship between the two variables was checked by Pearson correlation coefficients. A $\mathrm{P}$ value of less than 0.05 was considered to be statistically significant.

\section{Results}

Twenty-one women who had fetuses with gastroschisis were included in the study (gastroschisis group, $\mathrm{N}=21$ ). Gastroschisis was diagnosed by ultrasonography and confirmed after delivery. The chromosomal analysis of the gastroschisis group was normal. In the gastroschisis group there was one intrauterine death at 34 weeks, whereas the obstetrical outcome of the other affected fetuses was good. The control group consisted of 32 women submitted to amniocentesis performed because of abnormal triple screens indicating an increased risk for Down syndrome (control group, $\mathrm{N}=32$ ). None of the control group fetuses showed structural abnormalities in ultrasonography at the time of amniocentesis and none had chromosome abnormalities. All patients in the control group gave birth to a healthy child. The characteristics of both groups of patients are shown in Table 1 . The rates of nulliparity, the mean maternal and gestational ages and body mass index at the time of amniocentesis did not differ significantly between the two groups $(\mathrm{P}<0.05)$.

The mean concentrations of amino acids in the gastroschisis and control groups are given in Table 2 . The mean concentrations of essential and non-essential amino acids were significantly higher in the gastroschisis group than in the control group $(\mathrm{P}<0.05)$, whereas the mean concentrations of acidic amino acids (glutamine, glutamic acid, aspartic acid, asparagine), ornithine and cystathionine did not differ statistically between groups $(\mathrm{P}<0.05)$. There were significant positive correlations between maternal plasma and amniotic fluid concentrations of alanine, cysteine, glutamine, glycine, ornithine, proline, tyrosine, and essential amino acids in the gastroschisis group $(\mathrm{P}<0.05$, Table $3)$. None of the amino acids showed a statistically significant difference between maternal serum and amniotic fluid in the control group $(\mathrm{P}<0.05)$.

\begin{tabular}{|c|c|c|c|}
\hline Amino acid & $\begin{array}{l}\text { Gastroschisis group } \\
(\mathrm{N}=21)(\mu \mathrm{mol} / \mathrm{L})\end{array}$ & $\begin{array}{l}\text { Control group } \\
(\mathrm{N}=32)(\mu \mathrm{mol} / \mathrm{L})\end{array}$ & $P$ value \\
\hline Alanine & $177.9 \pm 49.2$ & $144.2 \pm 35.5$ & $0.006^{*}$ \\
\hline Asparagine & $26.9 \pm 4.6$ & $25.2 \pm 4.7$ & 0.217 \\
\hline Aspartic acid & $8.5 \pm 1.2$ & $8.9 \pm 4.6$ & 0.701 \\
\hline Cystathionine & $2.8 \pm 1.0$ & $2.5 \pm 1.4$ & 0.439 \\
\hline Cysteine & $27.5 \pm 2.9$ & $25.3 \pm 5.6$ & 0.101 \\
\hline Glutamic acid & $31.7 \pm 1.9$ & $32.5 \pm 6.5$ & 0.605 \\
\hline Glutamine & $42.0 \pm 5.7$ & $38.2 \pm 9.9$ & 0.11 \\
\hline Glycine & $145.4 \pm 41.9$ & $112.2 \pm 22.1$ & $0.002^{*}$ \\
\hline Histidine & $54.1 \pm 13.6$ & $31.5 \pm 7.4$ & $<0.001^{*}$ \\
\hline Isoleucine & $20.7 \pm 3.3$ & $17.7 \pm 3.3$ & $0.004^{*}$ \\
\hline Leucine & $66.3 \pm 14.6$ & $57.5 \pm 13.5$ & $0.029^{*}$ \\
\hline Lysine & $71.5 \pm 14.0$ & $43.4 \pm 20.0$ & $<0.001^{*}$ \\
\hline Methionine & $21.9 \pm 4.6$ & $10.6 \pm 2.6$ & $<0.001^{*}$ \\
\hline Ornithine & $20.2 \pm 4.0$ & $19.2 \pm 2.9$ & 0.088 \\
\hline Phenylalanine & $43.8 \pm 7.6$ & $32.6 \pm 9.9$ & $<0.001^{*}$ \\
\hline Proline & $212.4 \pm 20.0$ & $128.2 \pm 29.6$ & $<0.001^{*}$ \\
\hline Threonine & $102.6 \pm 8.5$ & $89.9 \pm 10.7$ & $<0.001^{*}$ \\
\hline Tryptophan & $11.6 \pm 2.3$ & $6.7 \pm 1.2$ & $<0.001^{*}$ \\
\hline Tyrosine & $45.2 \pm 9.3$ & $35.1 \pm 7.0$ & $<0.001^{*}$ \\
\hline Valine & $153.4 \pm 12.3$ & $113.1 \pm 16.5$ & $<0.001^{*}$ \\
\hline
\end{tabular}

Data are reported as means $\pm \mathrm{SD} .{ }^{*} \mathrm{P}<0.05$ for the gastroschisis group compared to control (Student $t$-test). 


\section{Discussion}

The results of the present study demonstrate that fetuses with gastroschisis have higher amniotic fluid concentrations of essential and non-essential amino acids than controls $(\mathrm{P}<0.05)$. This suggests that there is malabsorption of these amino acids or loss of essential amino acids from the fetus to the amniotic fluid. A similar phenomenon has been observed in studies on rabbit fetuses demonstrating that fetuses with iatrogenic gastroschisis are smaller and have a reduced uptake of amino acids and other nutrients compared to controls $(5,6)$.

Carroll et al. (3) reported that fetuses with gastroschisis have lower serum protein concentrations and higher amniotic fluid total protein levels than do cases of exomphalos or controls. Pathologic changes in the small intestine associated with gastroschisis, such as villous atrophy, increased mucosal per- meability, inflammatory bowel wall changes, and ischemia may contribute to the leakage of amino acids from the fetus to the amniotic fluid (3-5).

Midrio et al. (7) reported delayed maturation of intestinal pacemaker cells and smooth muscle cells in the rat model of gastroschisis which might explain the intestinal malfunction and reduced uptake of amino acids.

Blakelock et al. (8) studied 112 babies born with gastroschisis to explore the hypothesis that normal fetal gut function is needed for normal growth in late gestation and found that normal growth is dependent on a normally functioning gastrointestinal tract during this phase.

We found a significant positive correlation between maternal serum and amniotic fluid concentrations of essential and nonessential amino acids $(\mathrm{P}<0.05)$. Our hypothesis is that the changes in maternal serum

Table 3. Correlations between maternal serum (MS) and amniotic fluid (AF) amino acid levels in the gastroschisis group.

\begin{tabular}{lcccc}
\hline Amino acid & $\begin{array}{c}\text { Maternal serum } \\
\text { levels }(\mathrm{N}=21)(\mu \mathrm{mol} / \mathrm{L})\end{array}$ & $\begin{array}{c}\text { Amniotic fluid } \\
\text { levels }(\mathrm{N}=21)(\mu \mathrm{mol} / \mathrm{L})\end{array}$ & \multicolumn{2}{c}{ MS vs AF } \\
\cline { 4 - 5 } & & & r value & $\mathrm{P}$ value \\
\hline Alanine & $304.1 \pm 35.1$ & $177.9 \pm 49.2$ & 0.69 & $<0.001^{*}$ \\
Asparagine & $29.7 \pm 5.2$ & $26.9 \pm 4.6$ & 0.08 & $\mathrm{NS}$ \\
Aspartic acid & $9.1 \pm 2.3$ & $8.5 \pm 1.2$ & 0.02 & $\mathrm{NS}$ \\
Cystathionine & $4.0 \pm 2.5$ & $2.8 \pm 1.0$ & 0.09 & $\mathrm{NS}$ \\
Cysteine & $62.14 \pm 13.2$ & $27.5 \pm 2.9$ & 0.55 & $<0.001^{*}$ \\
Glutamic acid & $33.9 \pm 5.1$ & $31.7 \pm 1.9$ & 0.07 & $\mathrm{NS}$ \\
Glutamine & $488.5 \pm 21.1$ & $42.0 \pm 5.7$ & 0.85 & $<0.001^{*}$ \\
Glycine & $168.9 \pm 29.3$ & $145.4 \pm 41.9$ & 0.09 & $<0.05^{*}$ \\
Histidine & $100.3 \pm 23.4$ & $54.1 \pm 13.6$ & 0.60 & $<0.001^{*}$ \\
Isoleucine & $41.4 \pm 2.9$ & $20.7 \pm 3.3$ & 0.90 & $<0.001^{*}$ \\
Leucine & $98.2 \pm 6.6$ & $66.3 \pm 14.6$ & 0.67 & $<0.001^{*}$ \\
Lysine & $147.0 \pm 22.5$ & $71.5 \pm 14.0$ & 0.80 & $<0.001^{*}$ \\
Methionine & $33.3 \pm 4.6$ & $21.9 \pm 4.6$ & 0.61 & $<0.001^{*}$ \\
Ornithine & $31.2 \pm 5.4$ & $20.2 \pm 4.0$ & 0.58 & $<0.001^{*}$ \\
Phenylalanine & $55.1 \pm 10.0$ & $43.8 \pm 7.6$ & 0.29 & $<0.001^{*}$ \\
Proline & $278.0 \pm 23.9$ & $212.4 \pm 20.0$ & 0.04 & $<0.001^{*}$ \\
Threonine & $121.8 \pm 22.5$ & $102.6 \pm 8.5$ & 0.24 & $<0.001^{*}$ \\
Tryptophan & $37.5 \pm 2.0$ & $11.6 \pm 2.3$ & 0.97 & $<0.001^{*}$ \\
Tyrosine & $60.4 \pm 12.9$ & $45.2 \pm 9.3$ & 0.32 & $<0.001^{*}$ \\
Valine & $191.6 \pm 37.9$ & $153.4 \pm 12.3$ & 0.32 & $<0.001^{*}$ \\
& & &
\end{tabular}

Data are reported as mean \pm SD. NS $=$ not significant.

${ }^{*}$ The correlation was statistically significant $(P<0.05$; Pearson correlation coefficient test). 
concentrations of essential and non-essential amino acids might cause changes in amniotic fluid amino acid concentrations in pregnancies involving fetuses with gastroschisis. This might be the result of leakage from the intestinal fluid via a defective abdominal wall, intestinal dysfunction, increased mucosal permeability, or intestinal villous atrophy. Furthermore, prolonged exposure of the bowels to amniotic fluid might explain amino acid deficiency in fetus and increased concentrations of amino acids in amniotic fluid.

Human studies and experimental models have shown that amino acid uptake is decreased in fetuses with intrauterine growth restriction and that intrauterine growth restriction is likely to be associated with a shift in amino acid transport capacity and metabolic pathways within the fetoplacental unit $(9,10)$.

We found higher levels of amniotic fluid essential and non-essential amino acids in the gastroschisis group than in the control group which might explain intrauterine growth restriction in fetuses with gastroschisis.

The causes of growth restriction, fetal distress, and death in fetuses with gastroschisis may be complicated by amino acid deficiency as a result of malabsorption or loss, which might partly explain fetal morbidity and mortality. We speculate that replacement of essential and non-essential amino acids might improve the outcome of infants with gastroschisis during the neonatal period.

We found that amino acid levels of amniotic fluid were higher in pregnant women who had fetuses with a gastroschisis defect than in women with healthy fetuses, suggesting that there is malabsorption of amino acids or loss of amino acids from the fetus through the amniotic fluid. This is a preliminary study on amniotic fluid amino acid concentrations conducted on a small patient series. We think that it would be beneficial to conduct further studies with larger groups to determine the amino acid levels of fetuses with gastroschisis.

\section{References}

1. Kazaura MR, Lie RT, Irgens LM, Didriksen A, Kapstad M, Egenaes $J$, et al. Increasing risk of gastroschisis in Norway: an age-periodcohort analysis. Am J Epidemiol 2004; 159: 358-363.

2. Hoyme HE, Higginbottom MC, Jones KL. The vascular pathogenesis of gastroschisis: intrauterine interruption of the omphalomesenteric artery. J Pediatr 1981; 98: 228-231.

3. Carroll SG, Kuo PY, Kyle PM, Soothill PW. Fetal protein loss in gastroschisis as an explanation of associated morbidity. Am J Obstet Gynecol 2001; 184: 1297-1301.

4. Dykes EH. Prenatal diagnosis and management of abdominal wall defects. Semin Pediatr Surg 1996; 5: 90-94.

5. Shaw K, Buchmiller TL, Curr M, Lam MM, Habib R, Chopourian HL, et al. Impairment of nutrient uptake in a rabbit model of gastroschisis. J Pediatr Surg 1994; 29: 376-378.

6. Guo W, Swaniker F, Fonkalsrud EW, Vo K, Karamanoukian R.
Effect of intraamniotic dexamethasone administration on intestinal absorption in a rabbit gastroschisis model. J Pediatr Surg 1995; 30: 983-986.

7. Midrio P, Faussone-Pellegrini MS, Vannucchi MG, Flake AW. Gastroschisis in the rat model is associated with a delayed maturation of intestinal pacemaker cells and smooth muscle cells. J Pediatr Surg 2004; 39: 1541-1547.

8. Blakelock R, Upadhyay V, Kimble R, Pease P, Kolbe A, Harding J. Is a normally functioning gastrointestinal tract necessary for normal growth in late gestation? Pediatr Surg Int 1998; 13: 17-20.

9. Harding J. Nutritional causes of impaired fetal growth and their treatment. J R Soc Med 1999; 92: 612-615.

10. Regnault TR, Friedman JE, Wilkening RB, Anthony RV, Hay WJ. Fetoplacental transport and utilization of amino acids in IUGR - a review. Placenta 2005; 26 (Suppl A): S52-S62. 